\title{
Desenvolvimento de Interface de Usuário para a Melhoria da Consciência Situacional em Gerenciamento de Emergências
}

\section{Development of a User Interface for the Improvement of Situational Awareness in Emergency Management}

\author{
Leonardo Castro Botega ${ }^{1}$ \\ Allan Cesar Moreira de Oliveira \\ Regina Borges de Araújo ${ }^{2}$
}

Data de submissão: 24/08/2016, Data de aceite: 28/05/2017

\begin{abstract}
Resumo: Consciência Situacional (Situational Awareness - SAW) é um processo cognitivo amplamente difundido em áreas que demandam a tomada de decisão crítica e se refere ao nível de consciência que um indivíduo ou equipe detém sobre uma situação. No domínio de gerenciamento de emergências, a informação gerida por sistemas de apoio à avaliação de situações afeta a forma como os operadores humanos adquirem, mantêm e recuperam SAW. Tais rotinas, cruciais para a efetividade das atividades decisórias, são desafiadoras, não somente pela natureza crítica das situações, mas também devido à dinamicidade das informações que a compõem. Falhas de SAW podem induzir operadores humanos a erros no processo decisório e acarretar riscos à vida, ao patrimônio ou ao meio ambiente. Além disso, domínios críticos também exigem uma preocupação constante com a qualidade da informação, principalmente quando humanos são também fontes de informação, o que pode gerar incertezas. Neste contexto, interfaces orientadas a SAW exercem um papel fundamental, não somente para a representação de informações que podem ser incertas, mas também para promover uma gestão participativa da situação que evolui com o tempo. Este trabalho apresenta uma interface orientada por princípios de SAW e demonstra como inclui-la em um processo de avaliação de situações de emergências, composto por rotinas inovadoras de fusão, avaliação, representação e visualização de informações situacionais. Em estudo de caso, foram utilizados eventos de roubo relatados ao serviço de atendimento a emergências da Polícia Militar do Estado de São Paulo (PMESP). Uma avaliação de SAW foi conduzida com operadores da PMESP, que testaram e avaliaram a interface desenvolvida, revelando índices satisfatórios quanto ao entendimento de uma situação.
\end{abstract}

\footnotetext{
${ }^{1}$ Centro Universitário Eurípides de Marília, UNIVEM - Mirante, SP

\{botega@univem.edu.br\}

${ }^{2}$ Universidade Federal de São Carlos, UFSCar - São Carlos, SP

\{reginaedc.ufscar.br\}
} 


\begin{abstract}
Situational Awareness (SAW) is a cognitive process widely spread in areas that require critical decision-making and refers to the level of consciousness that an individual or team has about a situation. In the emergency management domain, the situational information inferred by decision support systems affects the way human operators acquire, maintain and recover SAW. Such routines, crucial for the effectiveness of decision activities, are challenging not only due to the situations critical nature, but also due to the dynamicity of their information. Failures in SAW can induce human operators to errors in decision-making, resulting in risks to life, assets or to the environment. In addition, critical domains also require a constant concern with the quality of information, especially when humans are also sources of information, which can lead to uncertainty. In this context, SAW oriented interfaces play a key role, not only for the representation of information that may be uncertain, but also to promote participatory management of the situation that evolves over time. This paper presents an interface oriented by principles of SAW and demonstrates how to include it in a process of assessment of emergencies, composed of innovative fusion routines, evaluation, representation and visualization of situational information. In a case study, we used robbery events reported to the service of the emergency response of the Military Police of São Paulo State (PMESP). A SAW evaluation was conducted with PMESP operators who have tested and evaluated the developed interface, showing satisfactory results for the understanding of a situation.
\end{abstract}

\title{
1 Introdução
}

SAW é um construto mental importante para os tomadores de decisão em diversas áreas críticas e diz respeito à percepção da presença e disposição de entidades de interesse em um ambiente, à compreensão do significado e importância de suas ações individuais e coletivas no espaço-tempo e à projeção de seus status em um futuro próximo.

No domínio de gerenciamento de emergências, SAW é um fator crucial para o sucesso das operações que envolvem humanos. Estar consciente de uma situação de emergência significa não somente deter meios para caracterizar entidades, eventos e suas relações, mas também subsídios para revelar tendências, incidência de ameaças e o aumento ou diminuição de riscos iminentes. Uma limitada SAW pode comprometer a compreensão de operadores humanos ao que realmente está acontecendo e levar a uma má tomada de decisões, o que pode resultar em consequências desastrosas para as pessoas, patrimônios ou meio ambiente.

Embora SAW não possa garantir decisões de melhor qualidade, a sua melhoria pode ajudar operadores humanos, sujeitos ao estresse, a manter um conhecimento mais amplo sobre eventos e situações em curso. Para operadores do serviço de atendimento 190 da Polícia Militar do Estado de São Paulo (PMESP), que podem ser rotineiramente sujeitos a alto nível de estresse, sobrecarga de informações e necessidade iminente de realização de múltiplas 
Desenvolvimento de Interface de Usuário para a Melhoria da Consciência Situacional em Gerenciamento de Emergências

tarefas, adquirir SAW é um desafio e também fundamental para a eficácia das atividades.

A sobrecarga de informação ainda pode aumentar quando outras fontes de dados são adicionadas aos sistemas reais (por exemplo, imagens de câmeras distribuídas pela cidade, informações de mídia social, etc.).

O processo de aquisição de SAW é ainda mais desafiador quando os dados são fornecidos pela inteligência humana (HUMINT) (1), como é o caso de um relato de um crime por uma vítima ou denunciante que chama o serviço 190 para obter ajuda.

Tipicamente, os dados HUMINT são incompletos, desatualizados, inconsistentes e às vezes até mesmo irrelevantes para o evento associado. Além disso, esses critérios também podem ser influenciados por fatores humanos, tais como estresse, medo e particularidades culturais.

A presença de dados e informações de baixa qualidade influencia os processos computacionais que utilizam relatos humanos como entrada de dados, que quando processados são úteis para desenvolver a SAW do operador humano.

Se há problemas associados à qualidade da informação, estes devem ser apresentados ao operador humano, sob o risco de gerar incertezas. Como representar graficamente as limitações de qualidade da informação e ao mesmo tempo prover meios para o usuário raciocinar sobre as incertezas é um desafio para a comunidade de engenharia cognitiva e interação humano-computador (1).

Aliada à complexidade inerente às informações dinâmicas e situações em constante evolução, a qualidade da informação, quando conhecida, pode influenciar a ação do operador humano, balizando suas decisões e orientando-o a confiar ou a trabalhar em busca da melhoria desta informação.

Para tentar superar tais problemas, interfaces dedicadas à obtenção, manutenção e retomada de SAW foram desenvolvidas. Tais interfaces preveem somente soluções ad-hoc de gestão de informações para apoiar mudanças ambientais apoiadas pela qualidade da informação e ajudar humanos especialistas a desenvolver SAW, além de serem limitadas em apoiar a gestão de informações (visualização, avaliação e refinamento) advindas e interpretadas por humanos (2).

Assim, o objetivo deste trabalho é apresentar o desenvolvimento de uma interface de usuário para amplificar a SAW de operadores humanos na análise situações de emergência que são dinâmicas, críticas, com a qualidade da informação explícita sob várias dimensões e que suporte a intervenção humana ao longo do processo de inferência e representação.

Especificamente, uma situação de roubo, conhecida pela sua complexidade de suas variáveis, é representada sob visualizações interativas adaptadas para explorar integralmente 
a promoção de SAW, alinhadas com os princípios difundidos por Endsley e Jones (2).

Na Seção 2 deste artigo são apresentados os conceitos relacionados a consciência situacional e o principal modelo citado na literatura. Na Seção 3 são apresentados os trabalhos relacionados a interfaces de usuário para SAW. A Seção 4 apresenta o processo de avaliação de situações de emergência no qual a interface de usuários é parte integrante. Na Seção 5 é apresentado o desenvolvimento da interface dedicada à SAW, validada sob um estudo de caso e finalmente, na Seção 6 são apresentados os resultados de uma avaliação com usuários especialistas no domínio, seguida de uma discussão na Seção 7.

\section{Consciência Situacional}

O termo Consciência Situacional é um importante conceito para ajudar a descrever a dinâmica da tomada de decisão humana. A existência do fenômeno é consensual, porém a definição concreta é discutível (3).

Uma definição bem aceita e frequente na literatura é proposta por Endsley (4) como sendo a "percepção de elementos no ambiente em um volume de tempo e espaço, a compreensão do seu significado e a projeção de seu estado em um futuro próximo".

Consciência situacional tornou-se objeto de estudo científico formal na década de 1980, embora seja um componente natural da cognição humana, sendo observada a partir de tempos pré-históricos, quando o homem necessitava estar ciente de muitos sinais do ambiente para ter sucesso em suas caças e evitar que se tornasse a presa (4).

A consciência situacional está presente em atividades operacionais ou corriqueiras onde humanos devem compreender uma situação por razões específicas. Um jogador necessita avaliar as condições em campo onde ocorre a partida, um motorista deve analisar todos os sinais no ambiente dinâmico da estrada, antes de decidir sobre uma ultrapassagem, um mergulhador precisar avaliar as condições do mergulho para que permaneça em segurança e todas as outras situações rotineiras e cotidianas em que é preciso decidir coisas simples como levar ou não um agasalho ao sair de casa.

Sob este prisma, pode-se observar que consciência situacional é altamente dependente de metas e objetivos de uma função ou trabalho específicos e que a importância da SAW como suporte ao processo decisório se aplica a quase todos os campos de atuação.

$\mathrm{Na}$ literatura, a pesquisa em SAW concentra-se principalmente no estudo de sua dinâmica em sistemas críticos ${ }^{3}$ para a aquisição, manutenção e retomada de SAW, tais como salas de emergência hospitalares, controle de tráfego aéreo, navegação fluvial, controle de

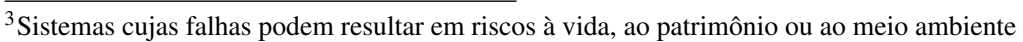


Desenvolvimento de Interface de Usuário para a Melhoria da Consciência Situacional em Gerenciamento de Emergências

usinas de energia, comando e controle policial/militares, gerenciamento de crises, resposta às emergências, dentre outros.

SAW é um produto do processo cognitivo, uma representação do conhecimento fundamental do estado e da mudança do mundo real. Com base nesta representação, o tomador de decisão pode decidir o que fazer sobre a situação e realizar quaisquer ações necessárias. É, portanto, representada como o principal precursor na tomada de decisão. Entretanto, uma boa SAW não garante necessariamente uma boa decisão. Desta maneira, melhorar a SAW aumenta a probabilidade de selecionar o curso de ação apropriado (2).

\subsection{O Modelo de Consciência Situacional de Endsley}

Similarmente à diversidade de definições, os modelos conceituais de SAW também são apresentados sob diferentes perspectivas. As divergências em torno desta área de estudos permeiam o debate sobre a natureza de SAW como processo ou produto aos termos de sua análise psicológica subjacente (5).

Endsley (4) aborda SAW como uma rotina de processamento de informação dirigida pela aquisição e uso da mesma. Outros modelos como o de Smith e Hancock (6) são uma interpretação ecológica sustentada pela análise perceptual do ciclo de modelo. Neste artigo será abordado o modelo de Endsley para o suporte ao processo de construção da interface a ser apresentada na Seção 4, considerando o potencial de aquisição e manutenção de SAW dirigido por dados e informações que um sistema de avaliação de situações de emergência se propõe a representar, habilitando uma visão sistêmica do processamento dos dados.

Para Endsley (4), SAW é composta por um núcleo de elementos que se relacionam em três níveis, os quais recebem influencias externas de tarefas e sistemas, como mostra a Figura 1. Já a Figura 2 apresenta tais níveis ilustrados individualmente.

- Nível um: Percepção dos elementos do ambiente. Trata-se do primeiro passo para obter SAW e remete a perceber os elementos relevantes do ambiente, seus atributos e estados, tipicamente de forma visual, auditiva, tátil, olfativa, pelo paladar, ou pela combinação dos sentidos.

- Nível dois: Compreensão da situação atual. Remete a compreender o que os elementos percebidos no ambiente significam uns em relação aos outros, e em relação às metas e objetivos de uma situação. Este processo envolve a integração de muitas partes de dados para formar a informação, priorizando a importância e o significado das informações combinadas.

- Nível três: Projeção dos estados dos elementos em um futuro próximo. Com base nos elementos identificados e o que eles significam em relação ao corrente objetivo, este 
Desenvolvimento de Interface de Usuário para a Melhoria da Consciência Situacional em Gerenciamento de Emergências

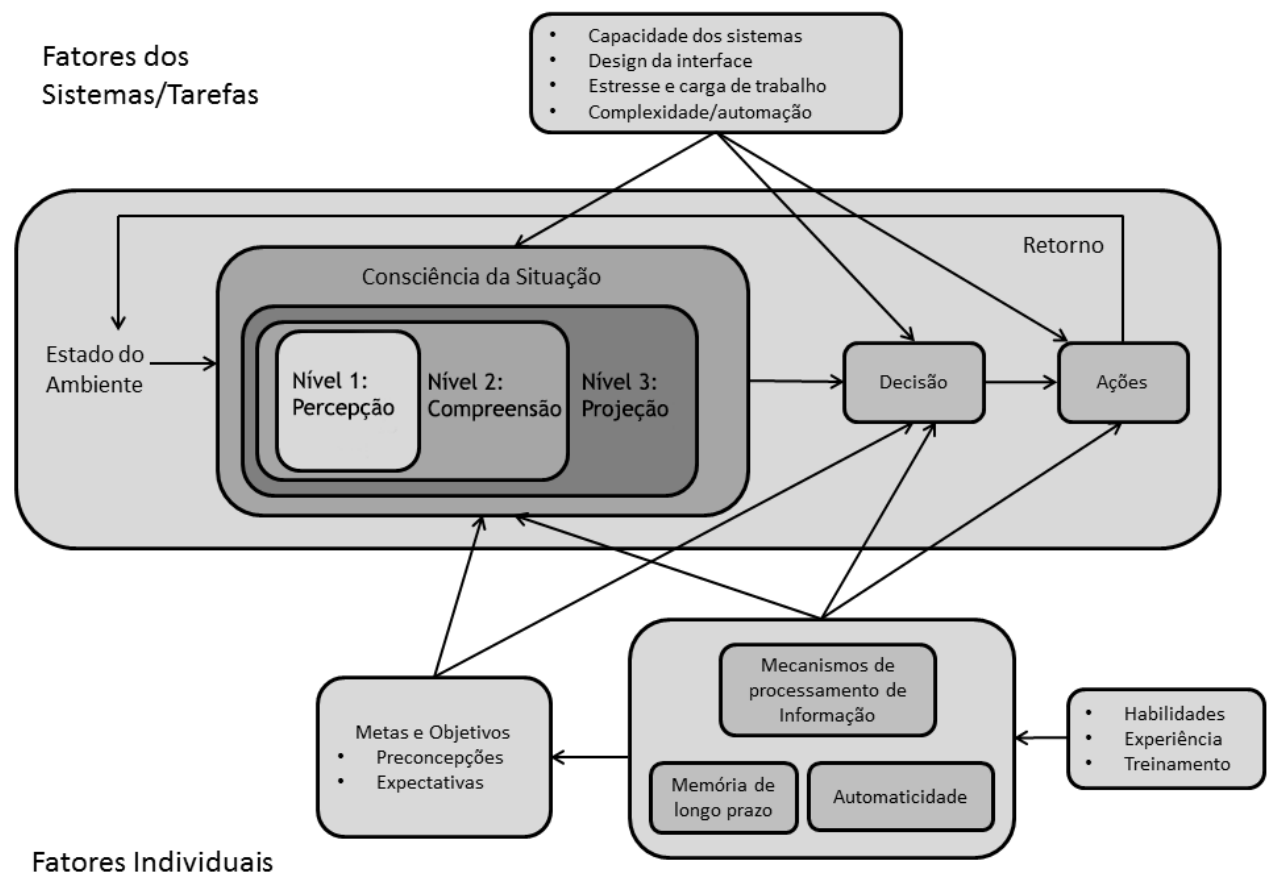

Figura 1. Modelo de Consciência Situacional de Endsley (Traduzido e Adaptado de Endsley (2))

nível compete à capacidade de predizer os seus estados futuros.

O nível três só é alcançado tendo um bom entendimento da situação (Nível dois). Entender a situação corrente para fazer projeções requer experiência no domínio. Sem a experiência ou um sistema de informação, com interfaces orientadas a SAW, as pessoas podem falhar nas fases iniciais da SAW e nunca prosseguirem para o nível três. Este nível sugere a combinação do que o indivíduo sabe sobre a situação atual com os seus modelos mentais do sistema, para prever o que é provável de acontecer em seguida (8).

No modelo de SAW de Endsley (2)(4), os sinais ou estados adquiridos do ambiente são utilizados como entradas para o processamento formado pelos níveis de percepção, compreensão e projeção.

Propositalmente o módulo de decisão é um estágio separado do núcleo, pois SAW é o 
Desenvolvimento de Interface de Usuário para a Melhoria da Consciência Situacional em Gerenciamento de Emergências

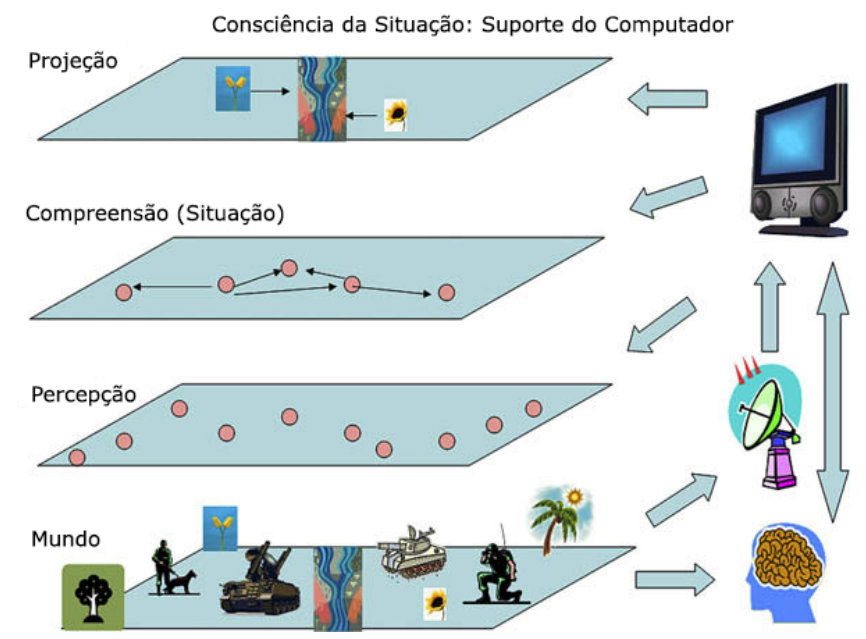

Figura 2. Níveis de Consciência Situacional (Traduzido e Adaptado de Kokar e Endsley (7))

principal precursor do processo de tomada de decisão. SAW é um modelo interno (mental) do operador sobre o estado do ambiente, e baseado nesta representação, o operador decide o que fazer sobre a situação.

O núcleo de SAW recebe influências diretas dos fatores externos dos indivíduos, das tarefas, dos sistemas e até do ambiente físico. Os sistemas influenciam o núcleo SAW por meio de sua interface e capacidades, aliado às características de cada tarefa no que tange à sua complexidade, automação, estresse e carga de trabalho que provoca no indivíduo. Já entre as características do ambiente que podem influenciar SAW estão: ruídos, luminosidade e até temperatura.

Tais fatores podem facilitar ou dificultar que o indivíduo alcance a SAW. Este por sua vez influenciará o núcleo SAW por meio de suas habilidades em executar as tarefas, seu nível de experiência e treinamento. Objetivos e metas direcionam a atenção para os sinais do ambiente assim como as expectativas de cada um, uma vez que as pessoas tendem a ver o que elas querem ver.

Os mecanismos de processamento de informação acionam meios de competir pela atenção do indivíduo diante de múltiplas fontes de informação. Projetar sistemas que distribuam a atenção adequadamente impactam na SAW. A automaticidade influencia a SAW em consequência da execução automática e repetida de ações rotineiras - pode-se exemplificar este aspecto, com a ação de trocar a marcha do carro ou parar no sinal vermelho, em que o motorista tem a falsa impressão de ter feito a ação sem raciocinar. 


\section{2 Áreas de Aplicação de Consciência Situacional}

Atualmente, SAW tem sido estudada em áreas tão diversas quanto medicina (anestesiologia), militar (comando e controle), navegação aérea, marítima e terrestre, manutenção de equipamentos, educação (estratégias de ensino-aprendizagem), entretenimento (jogos eletrônicos), esportes (táticas de jogos), dentre outras (2).

Inicialmente empregado no domínio da aviação, a generalização potencial da SAW pode ser confirmada pelos trabalhos de Gaba e Howard (9), que descreveram uma forte analogia entre os requisitos de SAW na aviação e na anestesiologia.

No domínio da aviação, os controladores de tráfego aéreo geralmente se referem à SAW como "a imagem da situação", que é uma representação mental da situação na qual se baseiam suas decisões (4). Para os controladores, "ter a imagem da situação" é o primeiro pré-requisito para lidar com o tráfego aéreo, realizando sua tarefa. "Perder a imagem da situação" é relatado como um dos maiores perigos para os controladores, o que os torna incapazes de prever a evolução da situação, detectar suficientemente cedo um problema ou um conflito, escolher a melhor resolução e em casos extremos, permitir que se estabeleçam incidentes ou acidentes (10).

Estudos de Shelton et al (11) mostram que na medicina, a consciência da situação é um fator humano de importância crítica para a segurança do paciente. Neste domínio, médicos e enfermeiros devem estar conscientes a todo instante do status do paciente, baseando-se em leituras de sensores e exames diversos. Perceber tais leituras e entender com antecipação o significado da evolução de seu estado é fundamental para estabelecer o melhor procedimento.

SAW é também um conceito amplamente difundido no domínio militar, devido à exigência de tomada de decisões assertivas em ambientes dinâmicos e críticos, no qual o tempo é um fator limitador. Neste contexto, a qualidade da decisão está relacionada com o nível de consciência que um indivíduo ou equipe tem a uma situação. Considerando o nível 1 de SAW, trata-se, por exemplo, de uma percepção dinâmica de um operador humano sobre o posicionamento e condição física de sua equipe, disponibilidade de armamentos ou a quantidade de tropas inimigas. Considerando o nível 2 de SAW, trata-se de uma compreensão sobre o avanço das tropas inimigas, o tempo até um combate iminente ou a possibilidade de deslocamento da equipe. Já em nível 3 de SAW, considera-se por exemplo se o grupamento inimigo, na atual posição ou velocidade, representa uma ameaça ou risco iminente à equipe no futuro próximo.

Operadores humanos de sistemas dedicados ao atendimento de emergências devem ser capazes, por exemplo, de perceber a presença de entidades e seus estados, como vítimas e criminosos, suas condições físicas, sua descrição, atitudes e comportamentos. Devem também compreender o significado das interações entre eles ou em relação ao ambiente, para caracterizar um crime específico, como por exemplo, se uma pessoa está ameaçando ou atacando 
Desenvolvimento de Interface de Usuário para a Melhoria da Consciência Situacional em Gerenciamento de Emergências

outra pessoa, e finalmente projetar novos ataques ou fugas iminentes.

Limitados subsídios para a tomada de decisão podem desencadear erros graves ao alocar recursos e ao determinar táticas para o atendimento, resultando em riscos à vida, ao patrimônio ou ao meio ambiente. Tais erros, descritos na próxima seção, podem ter causas diversas, mas podem ser resumidos em oito fatores determinantes que comprometem o processo de SAW e consequentemente a tomada de decisão.

\section{Trabalhos Relacionados}

A literatura apresenta soluções específicas tipicamente dedicadas a representar graficamente a imagem da situação (Situation Picture), sendo este o produto final de um processo de inferência acerca do que está ocorrendo em um ambiente monitorado. Ao representar a imagem da situação, que geralmente ocorre em tempo real e possui contextos altamente dinâmicos, interfaces dedicadas a SAW podem apresentar limitações, tais como: a dificuldade de representação ideal da qualidade da informação, limitados meios para a análise de partes componentes da informação situacional e limitadas formas de raciocínio sobre a informação quando o humano se encontra sob incertezas.

Entre os trabalhos relacionados há estruturas de interação para SAW, interfaces especializadas e sistemas gerais que se baseiam em como realizar o discurso humano-informação para a obtenção de SAW.

Nwiabu et al. (12) discutiram interfaces para sistemas militares para a predição de formação de hidratos em oleodutos e gasodutos submarinos. A interface baseia-se nos resultados de uma análise hierárquica de tarefa que se decompõe de um cenário complexo de pequenas tarefas. A interface é capaz de reconfiguração automática de se adaptar à situação atual e reduzir o esforço mental do operador. Este trabalho concentra-se da representação de dados preditivos, ao contrário da abordagem apresentada neste artigo, que busca representar dados em tempo-real à medida que são inferidos.

Yu et al. (13) apresentaram um novo contexto de visualização através da interface, que tem um motor de interpretação para contemplar as necessidades do operador e assim definir quais informações devem ser apresentadas para cada objetivo. A abordagem aqui apresentada busca contemplar objetivos locais e específicos de SAW, sem abdicar do exercício de atividades globais.

Onal et al. (14) desenvolveram uma interface com base em métodos para minimizar o esforço mental de máquinas de processamento de minérios pesados e assim melhorar a SAW. O layout da interface é baseado na interação guiada, painéis de suporte, mapas virtuais e múltiplas telas. Tais componentes são integrados para ajudar os operadores a evitar acidentes devido à sobrecarga de informação em tarefas operacionais. Uma análise de tarefas dirigida 
por objetivos (GDTA) foi aplicada para identificar requisitos. Os autores acreditam que esta abordagem promove um desvio de atenção, apesar da redução de esforço mental. Nesta nova abordagem, busca-se ampliar SAW e manter a atenção do usuário para o que se considera mais importante a cada instante, evidenciado pela análise de tarefas.

Gómez et al. (15) criaram um protótipo de interface para aumentar SAW dos operadores de sistemas de avaliação de situações de emergência, inteiramente baseada em contextos temporais para representar o cenário. As visualizações incluem a localização da equipe de salvamento e o local do acidente. Seu desempenho permite a alocação das equipes de resgate. Uma rede de sensores sem fio é responsável pela captura de dados heterogêneos e enviá-los para a interface do operador. Contextos temporais e outras questões que envolvem qualidade de dados, também são relevantes nesta abordagem, sendo aqui representadas visualmente para o acompanhamento pelo usuário.

Feng et al. (16) desenvolveram um sistema de apoio à decisão que incorpora SAW compartilhada entre agentes, os quais extraem a informação relevante sobre as entidades e as representa para o operador. Esses agentes têm o seguinte conjunto de metas e estratégias para cada nível SAW: missões, planos, ações e atributos físicos. Em seguida, eles são responsáveis por gerar recomendações sobre o cenário. A interface lida também com os aspectos espaço-temporais da evolução das missões. Nesta abordagem, as visualizações foram desenvolvidas para evoluírem juntas e manter o usuário atento às mudanças ao longo do tempo, sob diferentes representações, em sinergia com a dinamicidade dos dados deste domínio.

Além de serem soluções eficientes somente para os domínios de aplicações específicas, tais soluções são limitadas sobre a gestão da informação que está sendo propagada ao longo do ciclo de avaliação da situação. A abordagem do trabalho proposto inova na promoção da gestão de informações produzidas em cada fase, usando a representação de incertezas e métodos de aperfeiçoamento da informação como um recurso para controlar o conhecimento que é criado, representados e utilizados para avaliar situações.

Em complemento, soluções existentes são limitadas em promover o refinamento da informação pelo humano operador, que idealmente deve ser mais participativo, intenso, assertivo e subsidiado por metadados que complementem o conhecimento sobre o que ocorre em um ambiente monitorado. Tais abordagens atuais preveem uma atuação reativa, pontual e não coordenada frente às situações que a automação proporciona ao operador humano.

\section{Um Processo de Avaliação de Situações de Emergência}

Um Sistema de Avaliação de Situações tem como principal responsabilidade gerar subsídios para auxiliar a obtenção e manutenção de SAW de operadores tomadores de decisão. Um processo completo de avaliação de situações em cenários complexos destina-se a 
Desenvolvimento de Interface de Usuário para a Melhoria da Consciência Situacional em Gerenciamento de Emergências

adquirir, processar e representar partes de informação, que podem vir a contribuir com a avaliação da situação, além de suportar a participação de operadores no processo de refinamento do processo.

Um fator importante na avaliação da situação é entender a adequação das informações disponíveis e necessárias para a execução do processo de avaliação de situações. A Figura 3 apresenta um processo de Avaliação de Situações, destacando as etapas referentes à Interface de Usuários e o Refinamento de Informações, a serem discutidos em detalhes nas próximas seções. Este processo foi desenvolvido pelo Grupo de Interação Humano-Computador (GIHC) do Centro Universitário Eurípides de Marília (GIHC-UNIVEM). O processo pode ser resumido em seis sub-processos principais, cada um deles com mecanismos internos que desempenham papéis específicos, mas de grande contribuição para melhorar a qualidade das informações e, portanto, a SAW.

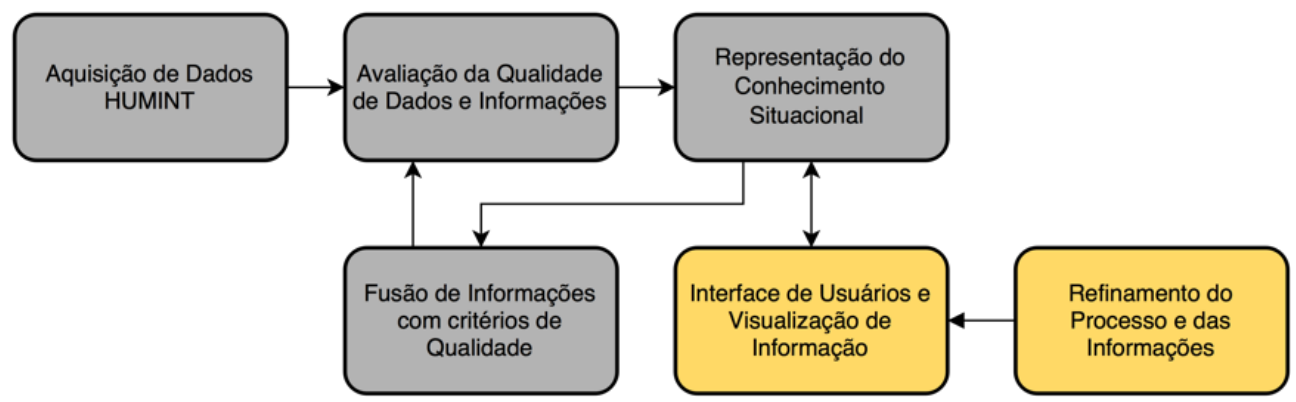

Figura 3. Processo de Avaliação de Situações destacando as etapas referentes à Interface de Usuários e o Refinamento de Informações

O processo de Avaliação de Situações apresentado tem início no módulo de Aquisição de Dados. Este processo é focado na transcrição de denúncias 190 e na aquisição de posts de redes sociais. Neste, as denúncias obtidas têm a análise gramatical e identificação de objetos relevantes nas sentenças (entidades como por exemplo vítimas, criminosos, locais do evento e objetos roubados). Este processo é denominado Processamento de Linguagem Natural (PLN). Como saída, é produzido um conjunto de objetos e propriedades denominado Situação. Tal situação é então submetida ao módulo seguinte para realizar uma avaliação da qualidade de dados e informações.

O módulo de Avaliação da Qualidade de Dados e Informações tem por objetivo, determinar uma sequência de atividades que represente de modo quantitativo a qualidade de dados de todo o processo. Neste módulo, a situação produzida é submetida a uma análise das seguintes dimensões de qualidade: completude (relacionada com a presença ou ausência) de objetos ou atributos que os descrevem; atualidade, que ajuda a determinar a "idade"da 
informação e assim tomar medidas oportunas; e incerteza, que é uma generalização de outras dimensões em uma única medida de qualidade (conjunto de objetos). Desta forma, cada objeto deve ter a sua própria pontuação de completude, caso estas não existam, índices de tempo e incertezas devem ser aplicados.

O módulo seguinte é o de Representação do Conhecimento Situacional, que utiliza ontologias para representar a informação semântica inferida ao longo do tempo. Tal modelo foi adotado porque, além de ter grande flexibilidade para representar semanticamente as relações entre os objetos, esta fornece suporte à inferência de informações não explícitas que métodos sintáticos de mineração são incapazes de inferir, considerando também a complexidade de se extrair significados de dados HUMINT. Esta ontologia foi desenvolvida com base na linguagem Web Ontology Language (OWL), que possui capacidade de demonstrar dados com a semântica agregada, de forma que um sistema consiga identificar e processar seus dados relacionais. Um exemplo da hierarquia de classes é apresentado pela Figura 4 e a Figura 5 mostra um exemplo de diagrama com propriedades de objeto da ontologia.

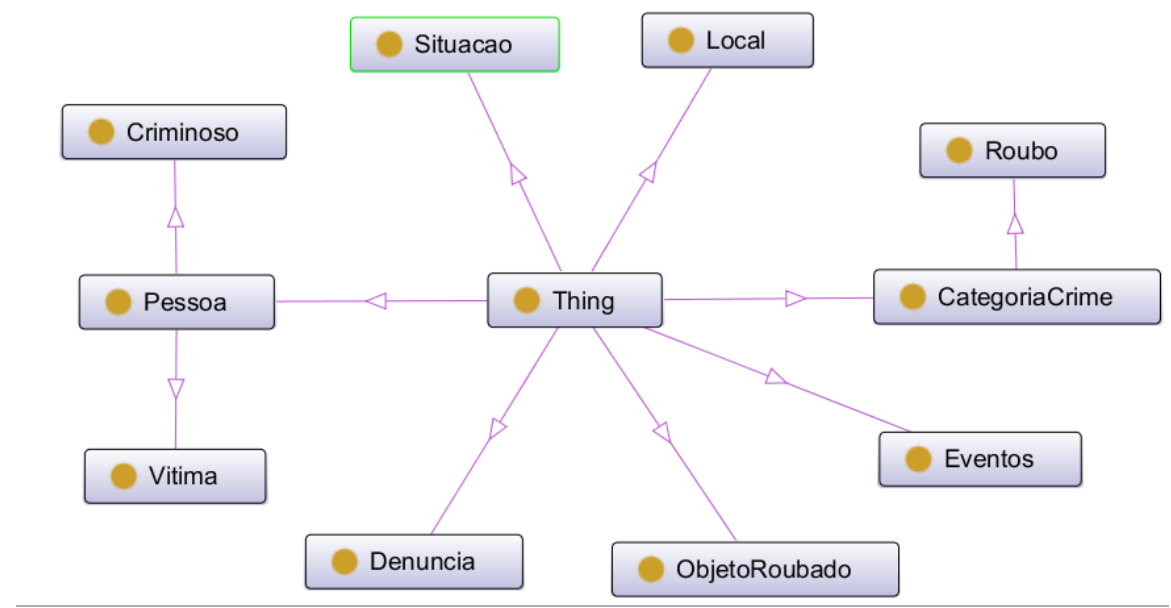

Figura 4. Exemplo de Hierarquia de classes da ontologia

A ontologia em OWL foi a base para a construção de um modelo de objeto JSON que incorpora todas as propriedades, classes e restrições contidas na ontologia, de modo que este objeto JSON se torna a instância das classes da ontologia. Ou seja, o modelo de representação de dados é a ontologia em OWL e as instâncias são os objetos JSONs gerados a partir deste modelo.

Nesta fase, já são conhecidos os objetos, atributos e possíveis relações entre eles. Em sistemas de avaliação de situação, são o Nível 1 e 2 da avaliação, também correspondente aos 
Desenvolvimento de Interface de Usuário para a Melhoria da Consciência Situacional em Gerenciamento de Emergências

níveis de percepção e compreensão de uma situação (17). É este conhecimento que deve ser codificado em visualizações e gerido pela interface de usuário.

Uma vez que o módulo de fusão for iniciado, na etapa de Fusão de Dados e Informações, é realizada a busca de informações sinérgicas entre as classes que já estão presentes na ontologia atual, e que podem deter informações de objetos, atributos, propriedades e índices de qualidade que possuam algum tipo de correspondência. Uma busca por mais informações que ainda não foram consideradas no processo é realizada, provenientes da mesma fonte ou de outras fontes de dados do processo de Aquisição de Dados. Como resultado, todas as informações iniciais que são submetidas ao processo de fusão são analisadas em busca de sinergia, com novos atributos, propriedades e até mesmo novos objetos encontrados durante o processo, de forma combinada e hierárquica, resultando em novas informações situacionais.

Por fim, a Interface de Usuários Orientada a SAW, principal foco deste trabalho, visa especificar uma sequência de atividades que auxilie no processo de gestão de informações situacionais críticas.

A interface tem por objetivo permitir que seus operadores atinjam, mantenham e propaguem SAW em relação às situações de emergência. Esta etapa deve representar situações adquiridas, processadas, integradas e representadas graficamente de forma significativa.

A etapa de Representação do Conhecimento Situacional é ligada diretamente à interface, abastecendo-a com o conhecimento agregado ao longo do processo, representado sob a

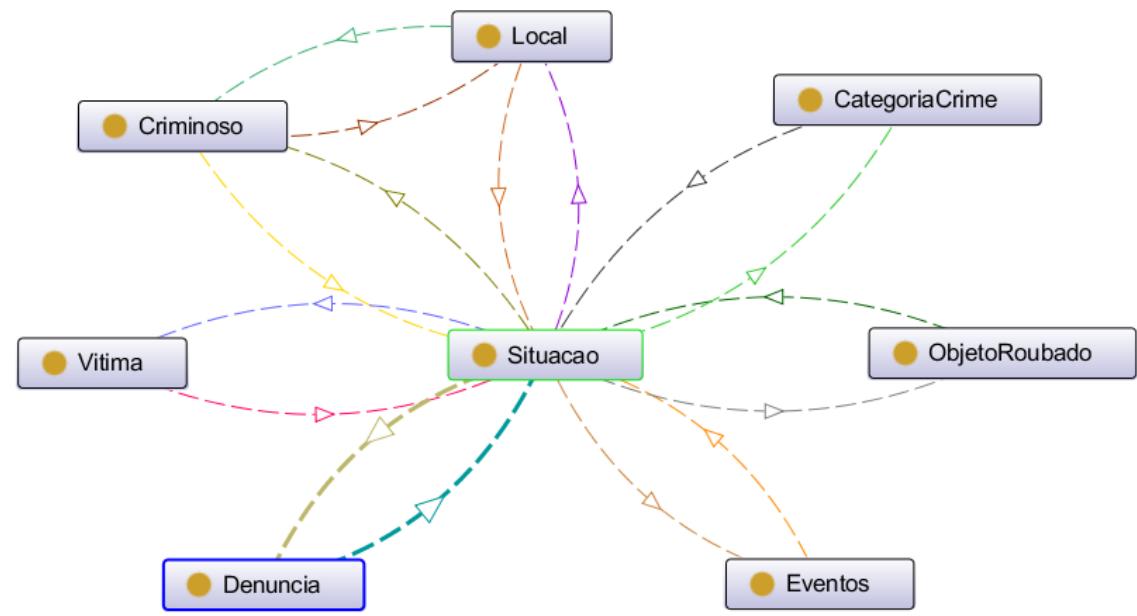

Figura 5. Exemplo de Propriedades de objeto das classes da ontologia 
forma de modelos semânticos (ontologias) cientes de qualidade de dados e informações.

Na próxima subseção será apresentado o desenvolvimento da interface para o enriquecimento de SAW em sistemas de gerenciamento de emergência. Este processo apresenta os resultados do desenvolvimento da interface envolvendo um estudo de caso que se refere a uma situação de roubo urbano, que é relatada por meio de denúncias à central de respostas a emergências da Polícia Militar do Estado de São Paulo (PMESP), bem como a inserção destas informações através do processo de avaliação de situações citado à cima.

As denúncias chegam a central da PMESP através de chamadas de emergência (190) ou posts de rede social. A cada nova denúncia novas entidades e atributos são apresentados e inferidos por um sistema de avaliação de situações (ex: criminoso, vítima, objeto e local).

Os módulos de aquisição de dados, avaliação de qualidade e fusão de dados trabalham em conjunto com a interface de usuário a fim de permitir que o operador tenha a todo instante, informações úteis ao processo de tomada de decisão, bem como o conhecimento do índice de qualidade das informações apresentadas.

No estudo de caso, é apresentada a interação que o operador pode ter em conjunto com as sugestões da interface, aceitando ou não a inserção das informações das denúncias à situação. Os passos de desenvolvimento abaixo listam e justificam as escolhas bem como apresentam à interface e as visões que a compõem.

\section{Desenvolvimento e Estudo de Caso de Interface de Usuário Orientada a SAW}

Visando o levantamento de requisitos para o desenvolvimento da Interface de Usuário Orientada a SAW, foram definidas duas abordagens: a Análise de Tarefas Dirigida por Objetivos (GDTA) e as diretrizes de projeto de interfaces para a obtenção e manutenção de SAW, introduzido por Endsley (2).

O GDTA ajuda os desenvolvedores de interfaces a listar todas as informações necessárias para estimular cada um dos três níveis de SAW (Percepção, Compreensão e Projeção), além das tarefas relacionadas para ajudar a atingi-los. Para obter essa informação, um questionário e uma observação em campo foram aplicados aos operadores humanos. Essa abordagem também ajudou a definir as prioridades e as decisões que devem ser executadas durante a análise da informação.

Nesta seção são apresentados os princípios para o desenvolvimento de cada componente da interface de usuário, implementada utilizado a linguagem JavaScript e a biblioteca D3 (18). AS escolhas de design foram baseadas no estado da arte em interfaces dedicadas a SAW. Ressalta-se também as vantagens e desvantagens de cada escolha de design para o 
Desenvolvimento de Interface de Usuário para a Melhoria da Consciência Situacional em Gerenciamento de Emergências

domínio de aplicação deste trabalho.

\subsection{Organizar as Informações de Acordo com os Objetivos}

O objetivo é analisar e avaliar situações de cenários complexos e dinâmicos, como os do domínio de gerenciamento de emergências, visando ajudar os operadores humanos a adquirirem SAW, usando as informações coletadas e processadas por um sistema de avaliação.

Para obter este resultado, a representação da informação na interface foi estruturada em torno de tal objetivo, desta maneira, é necessário que a interface não seja totalmente orientada por dados, mas sim visando a contribuição para SAW. Assim, a interface foi dividida em três visões complementares. A Figura 6 apresenta a visão geral da interface de SAW, dividida em três visões para a aquisição e manutenção de SAW em gerenciamento de cenários de emergências.

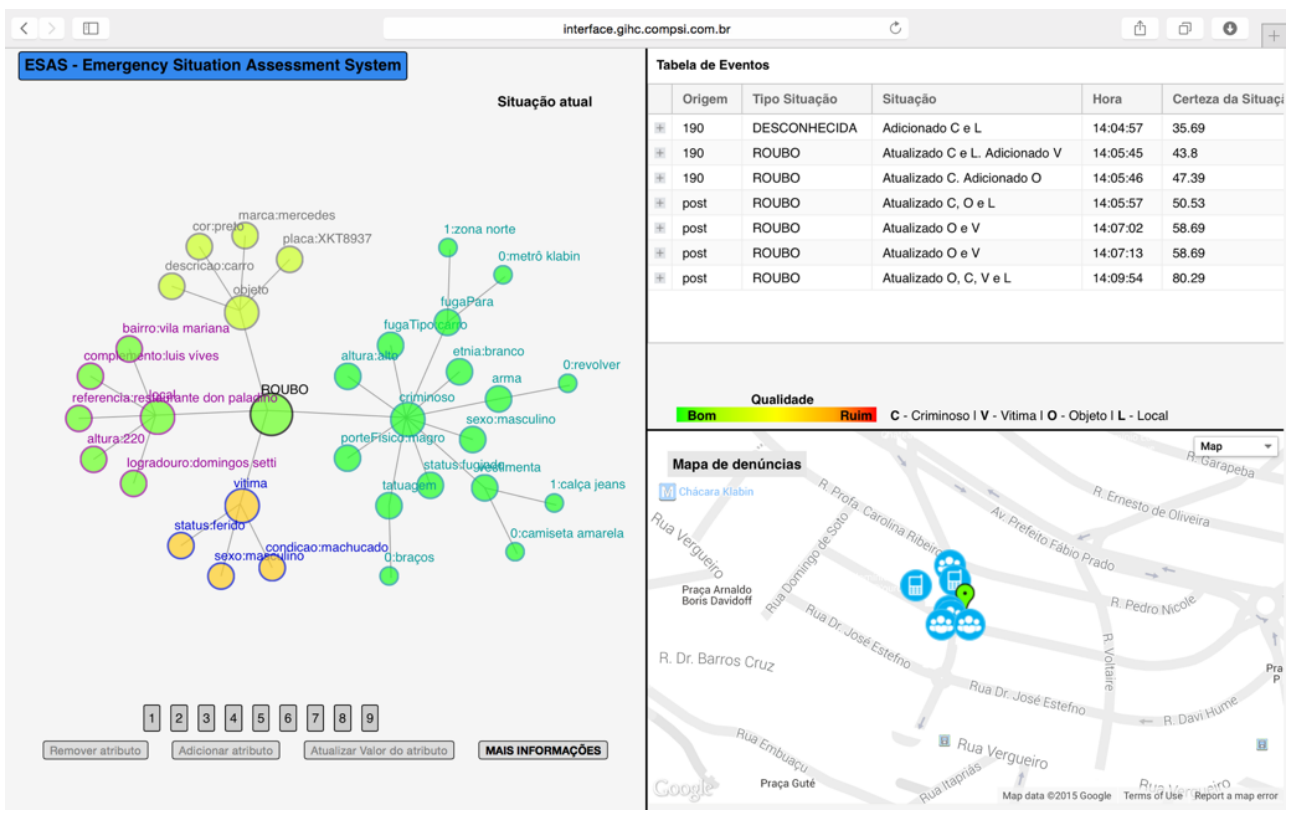

Figura 6. Visão geral da interface de usuário dividida em três visões para a aquisição e manutenção de SAW em gerenciamento de emergências, sendo estas: Grafo da Situação (lado esquerdo), Tabela de Eventos (canto superior direito) e Mapa de Denúncias (canto inferior direito)

A primeira visão (canto superior direito) na interface do usuário é denominada Tabela 
de Eventos. Nesta tabela são especificadas todas as transformações na qual a situação é submetida, como por exemplo: a adição de um local ou a atualização dos dados de uma pessoa ou objeto. Nesta figura ainda é possível observar a fonte de dados que deu origem à transformação, o tipo de situação até o momento, o instante em que a transformação ocorreu (ou o instante em que houve evolução na informação situacional) e o índice atual de confiança que a automação detém sobre a atual situação (certeza na situação).

O uso de sobreposições em um Mapa de Denúncias (canto inferior direito) é altamente recomendado para as operações de gerenciamento de emergências. Tal domínio é dependente de atributos de localização, cruciais para determinar o atendimento a um evento de emergência. Assim, esta visão é responsável por apresentar as origens das fontes de dados que estão em uso no processo de avaliação de situações, além do atual local aproximado do evento de interesse e acesso facilitado aos dados brutos de cada fonte, acionáveis por interação com as sobreposições.

O emprego do Grafo da Situação (lado esquerdo), é justificado pela necessidade de conhecimento hierárquico sobre como a informação é construída sobre as situações e seus objetos (19). É necessário que os operadores humanos saibam como cada situação é composta e com quais objetos e atributos. Situação é o nó central, composta pela relação entre objetos e seus atributos e ramificações.

Objetos podem ser identificados e não ter relações com nenhum outro, por isso, podem estar em hierarquias independentes. Neste caso, mesmo quando a composição não uma situação conhecida, a mesma deve ainda ser representada.

O tamanho indica a importância do nó na hierarquia, sendo o maior nó a situação propriamente dita (ex: emergência de roubo). O nível seguinte representa o conjunto de objetos (entidades) identificadas no processo de inferência (ex: pessoas, locais ou objetos). As folhas, nós de menor tamanho, representam os atributos dos objetos (ex: descrição de uma pessoa, um ponto de referência, status de uma pessoa).

O grafo também pode ser reorganizado e ter sua hierarquia atualizada ao longo do processo de análise, para implementar os refinamentos no processo, a ser discutido mais adiante. Toda e qualquer mudança em qualquer uma das visões reflete nas demais, atualizando suas informações, ou seja, a cada nova denúncia no Mapa de Denúncias e/ou evento na Tabela de Eventos, um novo nó ou hierarquia pode ser integrado ao grafo da Situação de maneira automática, caso venha a contribuir com a qualidade da situação.

Se uma informação ao ser processada vier a apresentar índices de qualidade limitados, esta informação será descartada automaticamente, pois poderá influenciar as informações já consolidadas e consequentemente a SAW do operador humano. 
Desenvolvimento de Interface de Usuário para a Melhoria da Consciência Situacional em Gerenciamento de Emergências

\subsection{Apresentar o Nível 2 de SAW Diretamente}

O objetivo é apresentar as informações necessárias para o segundo nível de SAW, visando apoiar a compreensão de resultados parciais mínimos diretamente, como um primeiro indício de uma situação que provavelmente está ocorrendo. A ideia é apresentar algumas informações já inferidas usando informações de primeiro nível, em vez de depender de cálculo mental do operador humano.

Algumas situações (compostas por objetos e atributos) podem ser calculadas a priori para reduzir o cálculo mental do operador que usa o sistema. Por exemplo, a parte automatizada pode inferir informações de várias entidades que remetem a um "objeto", identificada nas informações iniciais adquiridas. Neste momento não há nenhuma informação que qualifique o tipo ou descrição de um objeto supostamente roubado.

A Figura 7 indica que se trata de uma situação de roubo. Porém, esta faz referência apenas a um roubo de algo ainda não identificado. Neste contexto, uma fusão pode antecipar informações de Nível 2 de SAW diretamente ao integrar automaticamente novos dados aos da situação atual, considerando resultados parciais de fusão de dados como sendo informações de Nível 2.

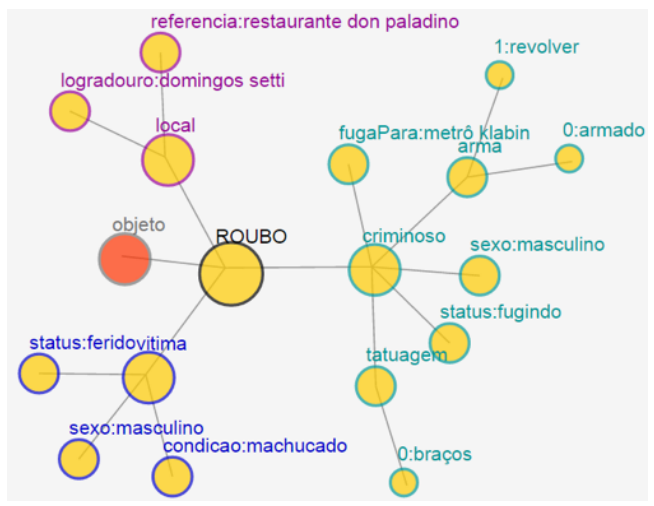

Figura 7. Representação do Grafo da Situação, referenciando um objeto roubado ainda não identificado

Assim, com a chegada de uma nova denúncia (Figura 8), também indiciando que houve um roubo de um objeto do tipo carro, o módulo de fusão de dados e informações pode confirmar a informação da primeira denúncia e já considerar a mesma como sendo única e de Nível 2 de SAW.

O mesmo processo ocorre quando há a necessidade de obter informações complementares que qualificam o objeto de roubo, também utilizando de fusão de dados automatizada. 
Desenvolvimento de Interface de Usuário para a Melhoria da Consciência Situacional em Gerenciamento de Emergências

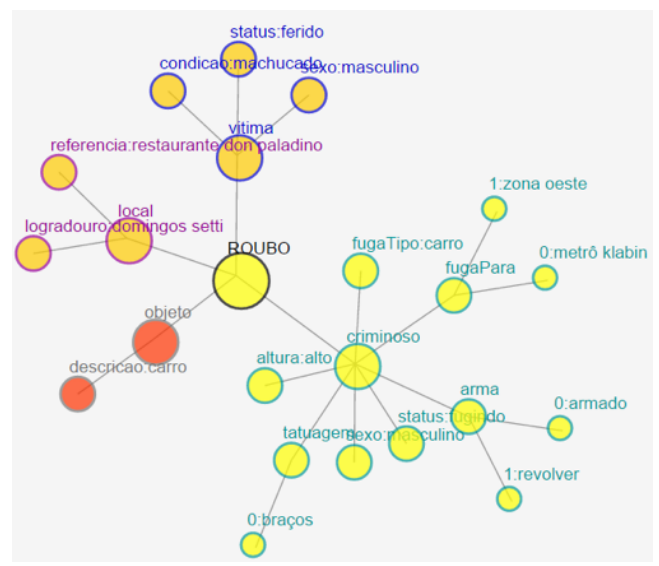

Figura 8. Representação do resultado da fusão de dados no Grafo da Situação, com as informações de uma nova denúncia (informação de Nível 2 de SAW). Há a confirmação do roubo de um carro

Assim, a interface pode contar com novas denúncias que especificam o objeto carro. A Figura 9 apresenta a especificação de atributos de que o carro roubado é da cor preta e a Figura 10, além de especificar a marca do carro, representa o aumento da confiança do sistema (cores em tons de verde) com a incorporação da nova informação integrada (19).

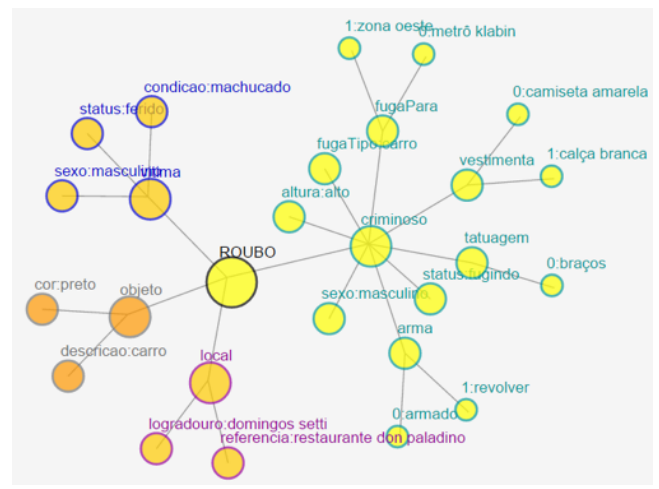

Figura 9. Representação da incorporação de novas denúncias no Grafo da Situação, confirmando o roubo de um carro da cor preta

Assim, em vez de apresentar somente as informações de Nível 1 separadamente, as mesmas são fundidas automaticamente, apresentando diretamente ao operador humano, uma 
Desenvolvimento de Interface de Usuário para a Melhoria da Consciência Situacional em Gerenciamento de Emergências

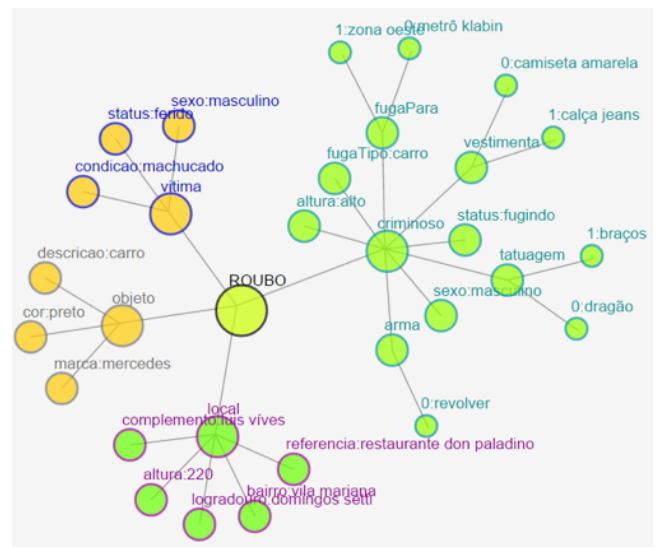

Figura 10. Representação do aumento da confiança do sistema (cores em tons de verde) com a incorporação da nova informação integrada ao Grafo da Situação

informação de menor dimensionalidade e maior significado.

Nos casos em que não ocorre uma fusão automática, o operador tem autonomia para realizar tal atividade em qualquer uma das três visões. Tal abordagem é conhecida como fusão em interface (interface fusion) e é uma das abordagens de refinamento para ser ainda mais detalhados. Essa abordagem ajuda a evitar a desordem da interface em caso de vários eventos simultâneos, mas negligencia uma granularidade maior no nível de atributos.

\subsection{Suportar a Consciência Situacional Global}

O conhecimento agregado sobre a situação deve estar sempre disponível. SAW Global é uma visão geral de toda a situação em uma linguagem de alto nível e de acordo com os objetivos do operador. SAW Global inclui também informações que são complementares à situação atual de interesse, mas que não necessariamente descrevem ou enriquecem tal situação, mas que compõem a visão de um cenário ou ambiente de interesse como um todo.

Desta maneira, ramificações isoladas aparentemente irrelevantes no grafo ou eventos divergentes na tabela e no mapa, que não compõem o objeto de interesse atual, devem ser considerados para o conhecimento global de SAW.

Na maioria dos sistemas de Avaliação de Situações, SAW global é sempre visível e pode ser crucial para determinar quais dos objetivos têm maiores prioridades. Para tal, o Grafo da Situação e a Tabela de Eventos podem ser expandidos e contraídos sob demanda para expor ou ocultar a hierarquia de objetos que compõe uma situação, visualmente e tex- 
tualmente. Assim, informações detalhadas sobre objetos podem estar sempre disponíveis, se solicitado. Situações complexas que contém muitos nós provocam automaticamente um efeito de zoom-out em sua visão. Não há um limite de quantidade de nós.

A Figura 6 também apresenta a Interface de Usuário Orientada a SAW orquestrando as suas visões de maneira a complementar a informação situacional presente em cada visão e promover a SAW global.

\subsection{Filtragem da Informação}

Para evitar a sobrecarga de informação, as informações não diretamente relacionadas a obtenção de SAW devem ser filtradas. A interface deve apresentar apenas as informações cruciais para alcançar os objetivos em cada tarefa a cada momento. Para tanto, foi desenvolvido um filtro interativo nas três visões da interface. Como a informação é inferida pela fase de aquisição, uma informação existente sobre qualquer um dos objetos, pode ser omitida ou destacada para uma análise específica.

Na Tabela de Eventos (Figura 11), detalhes sobre as transformações e os dados brutos de cada fonte de dados podem ser expandidos e omitidos sob demanda. No Grafo da Situação, os nós podem ser omitidos para ocultar determinados níveis da hierarquia da informação situacional. No Mapa de Denúncias, tipos de fontes de dados podem ser priorizadas para visualização.

Filtrar a informação é útil para reduzir o espaço de busca e determinar candidatos à fusão por meio da análise visual. No entanto, SAW não ocorre instantaneamente. Os operadores humanos levar um certo tempo para se orientar em relação a situações e atributos críticos. Uma filtragem ruim pode comprometer a visibilidade e a dinâmica do sistema que muda ao longo do tempo. Além disso, SAW global pode ser depredado e impede o humano de ser proativo.

\begin{tabular}{|c|c|c|c|c|c|}
\hline & Origem & Tipo Situação & Situação & Hora & Certeza da Situaçăo \\
\hline \multirow[t]{2}{*}{-} & 190 & DESCONHECIDA & Adicionado $\mathrm{C} \in \mathrm{L}$ & $14: 04: 57$ & 35.69 \\
\hline & \multicolumn{5}{|c|}{$\begin{array}{l}\text { Mais Informaçōes: acaba de acontecer um crime aqui na domingos setti um motorista foi ameaçado e } \\
\text { mandaram ele sair do veículo sem levar nada o bandido fugiu em direção ao metró klabin }\end{array}$} \\
\hline+ & 190 & ROUBO & Atualizado $\mathrm{C}$ e L. Adicionado $\mathrm{V}$ & $14: 05: 45$ & 43.8 \\
\hline+ & 190 & ROUBO & Atualizado C. Adicionado O & $14: 05: 46$ & 47.39 \\
\hline+ & post & ROUBO & Atualizado C, $\mathrm{O} \in \mathrm{L}$ & $14: 05: 57$ & 50.53 \\
\hline$\mp$ & post & ROUBO & Atualizado $\mathrm{O}$ & $14: 07: 02$ & 58.69 \\
\hline
\end{tabular}

Figura 11. Tabela de eventos com detalhes sobre as transformações e os dados brutos de cada fonte de dados 
Desenvolvimento de Interface de Usuário para a Melhoria da Consciência Situacional em Gerenciamento de Emergências

\subsection{Indicar Explicitamente a Imperfeição da Informação}

Humanos tendem a tratar a ausência de meta-informação como algo positivo (17)(19). Por exemplo, em caso de estimativas positivas, tende-se a achar que uma estimativa ausente também é positiva, quando na verdade, ela pode ser conflitante e imprecisa.

Além disso, o stress e a carga de trabalho podem levar operadores humanos a não prestarem atenção à ausência de informação. Mais ainda, estes podem se basear em suas experiências profissionais para analisar uma situação, enquanto outros dependem de indicações visuais. Neste trabalho, assim como na literatura, linhas tracejadas, cores e formas são utilizadas para representar o desconhecido (ausência de informação ou informação imperfeita). Os nós têm a sua cor interna atualizada toda vez que a qualidade da informação é corrigida, principalmente quanto à completude, apresentada como um dos requisitos de qualidade de informações no domínio de gerenciamento de emergências.

A cor do nó central do Grafo da Situação representa o grau de certeza da situação, isto é, o nível de confiança do sistema na informação como um todo, calculada em função das dimensões de completude e atualidade de todos os objetos). A cor dos nós do primeiro nível representa o nível de qualidade local de cada objeto/entidade, calculada em função da completude e atualidade da informação do objeto em particular. A cor dos nós do segundo nível acompanha a cor do primeiro nível.

Para a Interface de Usuário Orientada a SAW, quanto mais próximo um nó se aproxima da cor verde, maior é a qualidade das informações. Quanto mais próxima do vermelho, pior é a qualidade das informações, considerando o estímulo à percepção das cores na representação de informações. Este conceito se propaga também nas representações do Mapa de Denúncias, a qual indicam com um grau de certeza, o local aproximado da situação.

\subsection{Suportar a Verificação da Confiança na Informação Local e Global}

Tipicamente, a confiabilidade da fonte de dados é considerada pelo operador humano para apoiar e pesar suas opiniões sobre as informações produzidas e apresentadas (17)(19).

Porém, no contexto de uso de dados HUMINT, há uma grande chance de estes apresentarem algum tipo de problema de qualidade, comprometendo a confiança que o humano tem nos dados gerados por tais sensores.

Neste trabalho, para inferir e representar a confiabilidade da fonte de dado, foram adotados os índices de qualidade locais e globais que contribuem para a formação da confiabilidade dos sensores (contextos de leitura de um sensor humano). Quanto melhor a qualidade da informação gerada, maior a confiabilidade na fonte de dados.

Embora a confiabilidade dos valores possa ser apresentada numericamente, autores 
afirmam que o uso de níveis de luminância são aconselhados (quanto mais claro, mais confiável).

Assim, a Interface de Usuário Orientada a SAW mostra formas alternativas de representação da qualidade, sendo estas: as cores, tamanhos, formas e transparência dos nós no Grafo da Situação; as cores do local aproximado do evento no Mapa de Denúncias e finalmente a coluna "Certeza da Situação" na Tabela de Eventos.

Autores afirmam que quanto menor a quantidade de categorias que representam a qualidade da informação, mais rápida é a decisão do operador humano (elevado, médio, baixo) e estes tendem a aceitar melhor os índices mais baixos de qualidade. O uso de dados numéricos, analógicos e em classificação tendem a gerar decisões mais lentas (8).

Para a referida interface, emprega-se o uso de luminância, cores e formas, como discutido na seção anterior, representando graficamente as dimensões pertinentes ao domínio e a generalização certeza da situação.

Além disso, através da interação com o nó no Grafo da Situação, que representa a situação atual, com as sobreposições no mapa e com as entradas na tabela de eventos, os índices de qualidade da informação que compõem são revelados para ilustrar como tal qualidade global foi inferida. Essa abordagem permite aos operadores verificar índices de qualidade locais e globais sob demanda.

\subsection{Representar Eventos Históricos para Acompanhar a Evolução da Informação}

A interface do usuário apresenta acesso gráfico e interativo a informações históricas de eventos distribuídos ao longo do tempo. Para isso, foi desenvolvida uma escala temporal interativa (timeline) com intervalos de tempo, referentes aos instantes em que ocorreram transformações na informação situacional. Tal escala pode ser observada na Figura 6, na base do Grafo da Situação, representando o acesso pelo número/etapa da situação.

Tais intervalos remetem diretamente a cada linha na tabela de eventos e a uma situação do grafo. Em nossa abordagem de sistema de avaliação de situação, a situação é algo que evolui ao longo do tempo. Situações passadas também podem ser restauradas e inferidas novamente com novos parâmetros.

Desta maneira, operadores humanos podem acessar um evento histórico e, como resultado, a interface exibe a informação situacional composta por objetos e atributos anteriores ao presente momento, sob demanda. Ao selecionar um evento histórico, as outras visões da interface são redefinidas automaticamente para acomodar as informações da situação selecionada.

Assim, existe a possibilidade de retornar ao passado recente e também monitorar even- 
Desenvolvimento de Interface de Usuário para a Melhoria da Consciência Situacional em Gerenciamento de Emergências

tos em tempo-real, além de ser capaz de avançar diretamente para um momento específico. Como limitação, pode haver perda de foco sobre os acontecimentos atuais relevantes e confusão sobre a atualidade dos acontecimentos.

\subsection{Suportar a Atualização dos Níveis de Qualidade de Dados e Informações e o Ge- renciamento da Incerteza}

Uma vez que a informação situacional foi anteriormente inferida, os atributos referentes à qualidade da informação são também medidos e representados na interface, juntamente com as informações qualificadas, na forma de sugestões (cues) visuais que indicam tal qualificação. Neste contexto, a qualidade de dados e informações não apenas ajudam os operadores humanos a estabelecer um nível de confiança que devem depositar nas informações representadas, mas também orientam os mesmos a buscar recursos para a melhoria da qualidade da informação, em complemento às atividades que a automação já desempenhou, mas que eventualmente podem não ter sido suficientes para despertar a confiança do humano e estimular o processo de SAW.

Cabe então ao operador humano concordar e confiar nas as partes de informação situacional produzidas pela automação ou discordar e rejeitar a informação situacional preliminar, e trabalhar em benefício da melhoria da qualidade da informação e da aquisição de SAW.

A primeira forma de atuação do humano é no Refinamento da Aquisição, no qual o operador é capaz de atuar diretamente na fase de "Aquisição de Dados HUMINT" para requisitar novas fontes de informação, solicitar novas leituras dos diversos sensores e estabelecem novos parâmetros operacionais de busca de informação. Tais ações podem ser solicitadas via interação com menu no Mapa de Denúncias. Como resultado, são gerados novos insumos para os processos internos desta etapa em questão, ou seja, novos objetos, atributos e propriedades, desencadeando os demais processos que podem se beneficiar de uma nova aquisição (Avaliação da Qualidade de Dados e Informações e consequentemente a Fusão de Informações).

A segunda forma de atuação do humano, o Refinamento da Fusão, foi desenvolvido para permitir que operadores determinem manualmente os parâmetros de fusão, em vez de depender do processo automático de integração imediatamente após a aquisição de informação. Trata-se de uma nova parametrização do processo de fusão de dados e informações, operacionalizada pela interface orientada a SAW e implementada por filtros que determinam sob quais parâmetros a fusão será considerada. Tal ação pode ser ativada por interação com a Tabela de Eventos, a qual possibilita a seleção de parâmetros existentes e a indicação de novos parâmetros a serem considerados para uma fusão de dados. Esta ação também pode ser realizada diretamente do Grafo da Situação, ao escolher os nodos que o usuário considera sinérgicos para serem integrados visualmente. 
Em caso de fusão bem-sucedida, isto é, quando a informação é integrada e os níveis de qualidade aumentam, atualizando as cores dos nós do Grafo da Situação (locais e globais), se aproximando cada vez mais da cor verde. Em casos em que a fusão provocaria uma redução da qualidade dos dados, comuns quando novas informações são inconsistentes com as atuais, o usuário é avisado por janela pop-up e a informação é descartada. A fusão de dados ocorre em segundo plano para antecipar potenciais resultados, que são avaliados quanto à sua qualidade antes de serem consumidos pela interface. Caso o resultado comprometa a qualidade, de acordo com o uso de nossa metodologia, o usuário é avisado dessa provável piora e ajuda a evitar que o dado seja consumido.

Finalmente, a atuação do humano na Gestão do Conhecimento é a contribuição manual que operadores podem realizar para o conhecimento situacional, enriquecendo-o ao longo do tempo com informações advindas de seu próprio conhecimento em virtude de sua experiência, expertise ou ainda originário de fontes de informação externas que não foram ainda consideradas no processo de avaliação de situações e na interface.

Desta maneira, é possível que o operador humano insira, atualize ou remova objetos e atributos que compõem o conhecimento situacional diretamente, em interação intuitiva com o grafo da situação atual. A Figura 12 mostra o processo de inserção de uma parte de informação situacional diretamente no Grafo da Situação, ilustrando a escolha do objeto que vai receber um novo atributo, o cadastro do atributo e a nova ramificação no grafo. Não há uma posição predefinida para a alocação do novo nó filho ao nó pai correspondente, sendo que o grafo é auto-organizável.
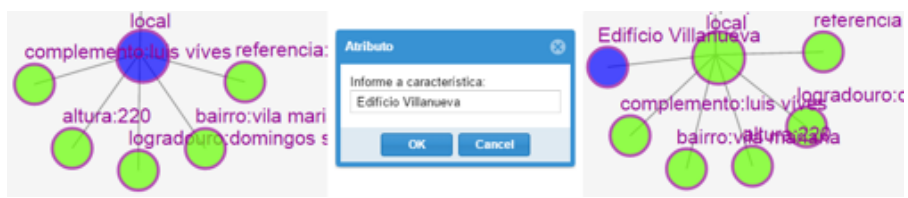

Figura 12. Representação do processo de inserção de uma parte de informação situacional diretamente no Grafo da Situação

Atuando diretamente no conhecimento situacional, informações inseridas, atualizadas ou removidas refletem nas demais etapas do processo de avaliação de situações e podem ser consideradas para Avaliação, Fusão e novamente na Representação semântica e gráfica na interface orientada a SAW.

Com estes mecanismos de refinamento da informação situacional, a interface apresenta o gerenciamento de informações de todo o processo e pode ser considerada como uma workbench de colaborarão onde ambos, sistema e o operador humano, que fornecem e transmitem informações como um conhecimento parcial que evolui com o tempo. Assim, toda vez que uma nova informação é fornecida por um desses atores, o outro é habilitado a processa-la 
Desenvolvimento de Interface de Usuário para a Melhoria da Consciência Situacional em Gerenciamento de Emergências

como parte de um novo conhecimento situacional.

No domínio de gerenciamento de emergências, a interface está presente onde um operador humano observa, se orienta, decide o que fazer e, em seguida, toma algumas medidas, que pode ser tanto a solicitação de refinamento ou uma decisão específica de domínio. Em nossa abordagem, este é o processo interno no qual o sistema compartilha o conhecimento parcial gerado pelas outras etapas, e em seguida, recebe as entradas dos operadores de forma cíclica.

\section{Avaliação com Usuários}

Para a realização dos procedimentos de avaliação da interface quanto à SAW proporcionada pela abordagem descrita, foram empregados 20 operadores humanos, membros da PMESP, todos do sexo masculino, com pelo menos um ano de experiência em atividades relacionadas à análise de situações e despacho de recursos para o atendimento a denúncias de crime. Em média, os operadores possuem cinco anos de experiência na atividade (mínimo de 1 e máximo de 25 anos de experiência), o que significa que todos os participantes são familiarizados com a tarefa de analisar e avaliar situações de emergência, considerados analistas despachadores experientes.

A estes operadores foi solicitado que operassem a interface em um ciclo de avaliação de uma situação, desde a disponibilização das denúncias, até a formação de uma situação considerada por eles mesmos suficiente para SAW, envolvendo todas as capacidades da interface.

Dessa maneira, ao final do ciclo de avaliação de situações, os avaliadores responderam um questionário sobre o componente Entendimento da Técnica de Pontuação de Consciência Situacional (Situation Awareness Rating Technique - SART) (20).

O componente Entendimento (nível de entendimento do operador), formado pelos componentes Quantidade de Informação (o quão suficiente é o volume de informação), Qualidade de Informação (o quão confiável é a informação), Familiaridade com a Situação (o quão familiar é a situação) e Entendimento da Situação (o quanto a informação foi compreendida) apresentou os seguintes resultados de acordo com a Figura 13 (escala de 0 a 10).

Quanto à Quantidade de informação, os índices com o uso da interface orientada a SAW mostraram-se elevados, dado os insumos que descrevem e qualificam a informação, que são as informações sobre a qualidade da situação, ajudando os operadores a entender a situação.

Já a Qualidade da Informação apresentou alto valor não somente por considerar que as informações propriamente ditas eram de alta qualidade, mas também quando estas foram 
Desenvolvimento de Interface de Usuário para a Melhoria da Consciência Situacional em Gerenciamento de Emergências

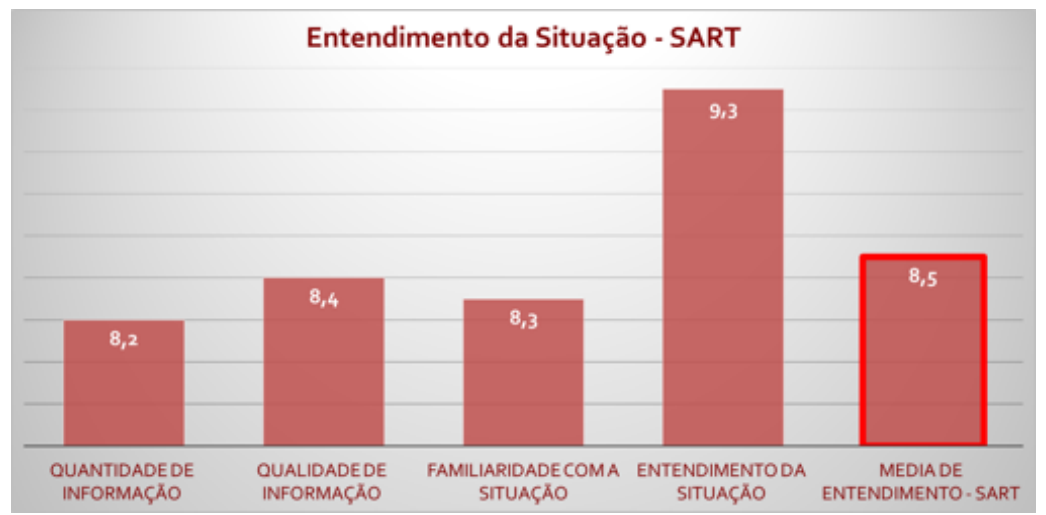

Figura 13. Resultado da Avaliação de SAW para o Componente Entendimento da Situação

inferidas com baixa qualidade e imediatamente representadas e qualificadas como tal, contribuindo para que o operador humano estabelecesse confiança no sistema.

Quanto à Familiaridade com a Situação, mudanças na situação não passaram despercebidas, sendo as variáveis incorporadas em seu devido contexto e todas devidamente justificadas. A interface evolui linearmente à situação e ajuda a tomar decisões embasando-se em qualidade de informações.

A hierarquia formada por partes da informação ajudou também a estabelecer o entendimento e a relação de cada parte da informação com o índice de confiança que a situação apresentava a cada ciclo de análise. Dessa maneira, a interface contribuiu para que o operador humano conhecesse a situação atual durante a realização da tarefa.

Finalmente, os participantes foram questionados quanto ao seu nível de entendimento geral sobre a situação, ou seja, se os mesmos compreenderam o que estava acontecendo no cenário durante a simulação. O resultado final quanto ao componente entendimento da avaliação SART apresentou-se com um alto índice, se comparado com os resultados apresentados na literatura (17)(20), indicando que operadores humanos compreenderam devidamente as situações sob análise.

\section{Discussão}

O processo interno especificado em "Interface de Usuários Orientada a SAW" foi proposto para incluir no processo de avaliação de situações de emergência, o suporte à representação gráfica do conhecimento agregado pelas fases anteriores e à gestão plena da informação 
Desenvolvimento de Interface de Usuário para a Melhoria da Consciência Situacional em Gerenciamento de Emergências

situacional e dos processos que contribuem para a sua formação.

A composição das visualizações é orientada pela "Representação do Conhecimento Situacional", que é atualizada e refletida na interface a cada nova inferência. Tal atividade habilita o operador humano a atuar de forma proativa frente à natureza dinâmica e complexa da informação produzida pelo sistema.

Neste contexto, a qualidade dos dados e informações, quantificada e representada graficamente promove o acompanhamento mais rico de tal evolução, estimulando a percepção e até mesmo a compreensão direta da informação situacional. Uma vez melhor orientado pelas questões referentes à qualidade, o humano é capaz de tomar melhores decisões quanto à necessidade de refinamento ou encerramento do processo de avaliação da situação.

Como já apresentado, todas as interações dos processos internos do modelo com a atual parte de informação em análise, inclusive via interface de usuários, geram um efeito de propagação e evolução no conhecimento situacional, refletindo na atuação de todas as demais etapas. Com este processo interno, o operador humano foi habilitado a atuar sobre partes da informação em maior nível de granularidade, influenciando em sua composição. A atuação direta no conhecimento situacional permite também que fontes externas ao sistema sejam também consideradas, inseridas no contexto e incorporadas em tempo-real à situação representada.

É importante ressaltar que um processo de avaliação de situações suporta o processo de inferência não-linear de situações, ou seja, é possível que cada ciclo de análise seja desencadeado e retomado por qualquer uma das etapas do modelo, além de que o subproduto de cada fase pode influenciar a atuação humana e o mesmo influenciar cada uma das demais etapas de forma independente e assíncrona.

Entretanto, é possível observar, que o processo completo deve necessariamente seguir uma ordem pré-determinada para a geração de entradas e saídas que contribuam para o abastecimento de demais processos internos e para a continuidade da avaliação de uma situação.

Adicionalmente, não é obrigatório que todas os processos internos sejam ativados para que o operador humano determine o encerramento do ciclo de analise, ou seja, processos como a fusão propriamente dita, podem não ser necessários para atingir SAW.

Como limitações da interface apresentada, destaca-se a ausência de situações simultâneas para fins de comparação (de um mesmo evento ou de outro) e uma forma mais efetiva de ilustrar objetos e atributos ausentes, ao invés de apenas quantificar os objetos pela ausência de atributos, mostrando "quais" não compõem a atual situação.

Assim, conclui-se que aumentar os poderes do operador e também da automação, intensificando seu relacionamento através da qualidade da informação para construir uma imagem mais fidedigna das situações, tem o potencial para promover a aquisição, manutenção 
Desenvolvimento de Interface de Usuário para a Melhoria da Consciência Situacional em Gerenciamento de Emergências

e retomada de SAW, o que ainda não foi largamente explorado.

\section{Contribuição dos Autores}

- Leonardo foi o autor principal e responsável pela pesquisa científica como um todo. Desenvolveu a interface e escreveu $90 \%$ do artigo.

- Allan contribuiu com resumo e introdução do trabalho, além de revisar o artigo como um todo.

- Regina, além de contribuir com o processo de revisão, foi a orientadora do trabalho.

\section{Referências}

1 BLASCH, E. et al. Revisiting the JDL model for information exploitation. In: $16 \mathrm{TH}$ INTERNATIONAL CONFERENCE ON INFORMATION FUSION, 16., 2013, Istanbul, Turkey. Anais... Piscataway, NJ, USA: IEEE, 2013. p. 129-136.

2 ENDSLEY, M. R.; JONES, D. G. Designing for Situation Awareness: An Approach to User-Centered Design. Boca Raton, FL, USA: CRC Press, 2012.

3 BOSSÉ, E.; ROY, J.; WARK, S. Concepts, Models, and Tools for Information Fusion. Norwood, MA, USA: Artech House, 2007.

4 ENDSLEY, M. R. Design and evaluation for situation awareness enhancement. In: 32ND HUMAN FACTORS AND ERGONOMICS SOCIETY ANNUAL MEETING, 32., 1988, Santa Monica, CA, USA. Anais... Santa Monica, CA, USA: Human Factors and Ergonomics Society, 1988. p. 97-101.

5 SALMON, P. M. et al. What really is going on? Review of situation awareness models for individuals and teams. Theoretical Issues in Ergonomics Science, Oxfordshire, England, v. 9, n. 4, p. 297-323, 2008. Disponível em: <http://dx.doi.org/10.1080/14639220701561775>. Acesso em: 2 mar. 2017.

6 SMITH, K.; HANCOCK, P. A. Situation awareness is adaptive, externally directed consciousness. Human Factors, Santa Monica, CA, USA, v. 37, n. 1, p. 137-148, 1995. Disponível em: <http://dx.doi.org/10.1518/001872095779049444>. Acesso em: 2 mar. 2017.

7 KOKAR, M. M.; ENDSLEY, M. R. Situation awareness and cognitive modeling. IEEE Intelligent Systems, IEEE Educational Activities Department, Piscataway, 
Desenvolvimento de Interface de Usuário para a Melhoria da Consciência Situacional em Gerenciamento de Emergências

NJ, USA, v. 27, n. 3, p. 91-96, may 2012. ISSN 1541-1672. Disponível em: <http://dx.doi.org/10.1109/MIS.2012.61>. Acesso em: 5 mar. 2017.

8 ENDSLEY, M. R.; CONNORS, E. S. Situation awareness: State of the art. In: IEEE POWER AND ENERGY SOCIETY GENERAL MEETING - CONVERSION AND DELIVERY OF ELECTRICAL ENERGY IN THE 21ST CENTURY, 6., 2008, Pittsburgh, PA, USA. Anais... Piscataway, NJ, USA: IEEE, 2008. p. 1-4. ISSN 1932-5517.

9 GABA, D. M.; HOWARD, S. K.; SMALL, S. D. Situation awareness in anesthesiology. Human Factors, Santa Monica, CA, USA, v. 37, n. 1, p. 20-31, 1995. Disponível em: <http://dx.doi.org/10.1518/001872095779049435>. Acesso em: 10 mar. 2017.

10 EUROCONTROL. The development of situation awareness measures in ATM systems. Brussels, 2003. v. 1, 88 p.

11 SHELTON, C. L. et al. Real-time situation awareness assessment in critical illness management: adapting the situation present assessment method to clinical simulation. Quality and Safety in Health Care, BMJ Publishing Group Ltd, London, England, v. 22, n. 2, p. 163-167, 2013. ISSN 2044-5415. Disponível em: <http://qualitysafety.bmj.com/content/22/2/163>. Acesso em: 20 mar. 2017.

12 NWIABU, N. et al. User interface design for situation-aware decision support systems. In: IEEE INTERNATIONAL MULTI-DISCIPLINARY CONFERENCE ON COGNITIVE METHODS IN SITUATION AWARENESS AND DECISION SUPPORT, 2., 2012, New Orleans, LA, USA. Anais... Piscataway, NJ, USA: IEEE, 2012. p. 332-339. ISSN 2379-1667.

13 YU, S.; DENG, L.; ZHANG, Y. Visualization user interface for decision support systems. In: NINTH INTERNATIONAL CONFERENCE ON HYBRID INTELLIGENT SYSTEMS, 9., 2009, Shenyang, China. Anais... Piscataway, NJ, USA: IEEE, 2009. v. 1, p. 63-66.

14 ONAL, E. et al. From theory to practice: How designing for situation awareness can transform confusing, overloaded shovel operator interfaces, reduce costs and increase safety. In: 30TH INTERNATIONAL SYMPOSIUM ON AUTOMATION AND ROBOTICS IN CONSTRUCTION AND MINING (ISARC), 30., 2013, Montreal, Canada. Anais... [S.1.]: IAARC, 2013. p. 1517-1525.

15 GOMEZ, L.; LAUBE, A.; ULMER, C. Secure sensor networks for public safety command and control system. In: IEEE CONFERENCE ON TECHNOLOGIES FOR HOMELAND SECURITY, 3., 2009, Waltham, MA, USA. Anais... Piscataway, NJ, USA: IEEE, 2009. p. 59-66. 
Desenvolvimento de Interface de Usuário para a Melhoria da Consciência Situacional em Gerenciamento de Emergências

16 FENG, Y.-H.; TENG, T.-H.; TAN, A.-H. Modelling situation awareness for context-aware decision support. Expert Systems with Applications: An International Journal, Pergamon Press, Inc., Tarrytown, NY, USA, v. 36, n. 1, p. 455-463, jan. 2009. ISSN 0957-4174. Disponível em: <http://dx.doi.org/10.1016/j.eswa.2007.09.061>. Acesso em: 19 abr. 2017.

17 BOTEGA, L. C. Modelo de Fusão Dirigido por Humanos e Ciente de Qualidade de Informação. Tese (Doutorado) - Universidade Federal de São Carlos, São Carlos, SP, Brasil, 2016.

18 BOSTOCK, M.; OGIEVETSKY, V.; HEER, J. D3 data-driven documents. IEEE Transactions on Visualization and Computer Graphics, IEEE Educational Activities Department, Piscataway, NJ, USA, v. 17, n. 12, p. 2301-2309, dec 2011. ISSN 1077-2626. Disponível em: <http://dx.doi.org/10.1109/TVCG.2011.185>. Acesso em: 20 abr. 2017.

19 RIVEIRO, M. Evaluation of uncertainty visualization techniques for information fusion. In: 10TH INTERNATIONAL CONFERENCE ON INFORMATION FUSION, 10., 2007, Quebec, Canada. Anais... Piscataway, NJ, USA: IEEE, 2007. p. 1-8.

20 TAYLOR, R. M. Situational awareness rating technique (SART): The development of a tool for aircrew systems design. In: AGARD AMP SYMPOSIUM ON SITUATIONAL AWARENESS IN AEROSPACE OPERATIONS, 1989, Neuilly-sur-Seine, France. Anais... Neuilly-sur-Seine, France: NATO AGARD, 1989. Disponível em: $<$ https://www.bibsonomy.org/bibtex/23d10f7249aca214ef1be7f4e669ed53d/jhandcock>. Acesso em: 17 mar. 2017. 